\title{
Redescription of Mymarilla Westwood, new synonymies under Cremnomymar Ogloblin (Hymenoptera, Mymaridae) and discussion of unusual wings
}

\author{
John T. Huber' \\ I Natural Resources Canada, clo Canadian National Collection of Insects, AAFC, K. W. Neatby building, 960 \\ Carling Avenue, Ottawa, ON, K1A 0C6, Canada \\ Corresponding author: John T. Huber (john.huber@agr.gc.ca)
}

Academic editor: M. Engel | Received 6 September 2013 | Accepted 8 October 2013 | Published 29 October 2013

Citation: Huber JT (2013) Redescription of Mymarilla Westwood, new synonymies under Cremnomymar Ogloblin (Hymenoptera, Mymaridae) and discussion of unusual wings. ZooKeys 345: 47-72. doi: 10.3897/zookeys.345.6209

\begin{abstract}
The monotypic genus Mymarilla Westwood is known only from St. Helena, a remote island in the South Atlantic Ocean. The peculiar species M. wollastoni Westwood (Mymaridae) is redescribed and illustrated from non-type material. Mymarilla is compared with Cremnomymar Ogloblin spp. from the Juan Fernández Islands in the South Pacific Ocean. Stephanodes Enock is shown to be the most likely sister genus to Mymarilla. Nesopolynema Ogloblin, syn. n., Oncomymar Ogloblin, syn. n., Scolopsopteron Ogloblin, syn. n., are placed in synonymy under Cremnomymar and their species transferred as Cremnomymar caudatum (Ogloblin 1952), comb. n., C. dipteron (Ogloblin 1957), comb. n., and C. kuscheli (Ogloblin 1952), comb. n. Wing shape and wing reductions in Mymaridae are discussed in relation to biogeography, particularly with respect island faunas and to four genera, Cremnomymar, Mymarilla, Parapolynema Fidalgo, and Richteria Girault, some or all of whose species have more or less convex fore wings.
\end{abstract}

\section{Keywords}

Mymaridae, Mymarilla wollastoni, Cremnomymar, Richteria, Parapolynema, wing modifications, island faunas

Copyright John T. Huber. This is an open access article distributed under the terms of the Creative Commons Attribution License 3.0 (CC-BY), which permits unrestricted use, distribution, and reproduction in any medium, provided the original author and source are credited. 


\section{Introduction}

The small, remote South Atlantic island of St. Helena contains a high proportion of endemic species but among the Hymenoptera only the Formicidae have been systematically studied (Wetterer et al. 2007). Among the insects, one of the most remarkable is Mymarilla wollastoni Westwood (Hymenoptera: Mymaridae). Although the species was described briefly from both sexes (Westwood 1879), it is instantly recognizable from the original illustrations that show the peculiar, strongly convex fore wings. Annecke and Doutt (1961) redescribed the species in greater detail, designated a lectotype, and cleared up the confusion by previous authors over what species should be included in Mymarilla Westwood. Subba Rao (1976) illustrated the species with a habitus drawing. Mymarilla is redescribed from material other than the original type series and is compared with new material of Cremnomymar Ogloblin and its synonyms (proposed below) from the Juan Fernández Islands, about $600 \mathrm{~km} \mathrm{~W}$. of Chile in the South Pacific Ocean. Wing shape, and wing reduction and/or convexity is discussed in relation to geographical distribution of Mymaridae.

\section{Methods}

Morphological terms follow Gibson (1997) and Huber (2012). Measurements are in micrometres $(\mu \mathrm{m})$. Photographs of critical point dried and card mounted specimens were taken with a ProgRes C14plus digital camera attached to a Nikon Eclipse E800 compound microscope, and the resulting layers combined electronically using AutoMontage ${ }^{\bullet}$ or Zyrene Stacker ${ }^{\bullet}$ and retouched as needed with Adobe ${ }^{\circ}$ Photoshop CS6 ${ }^{\circ}$. Specimens of Cremnomymar were gold coated for scanning electron micrography, using the techniques described in Bolte (1996).

Specimens are in the following institutions.

BMNH The Natural History Museum (formerly British Museum [Natural History]), London, England (G. Broad).

CNC Canadian National Collection of Insects, Ottawa, Canada.

MRAC Musée Royal de l'Afrique Centrale, Tervuren, Belgium (E. de Coninck).

OUMNH Oxford University Museum of Natural History.

\section{Systematics}

\section{Mymarilla Westwood}

http://species-id.net/wiki/Mymarilla

Mymar: Westwood 1879: 585 (M. wollastoni included, together with another, correctly placed species). 
Mymarilla Westwood, 1879: 585 (footnote) + figs 8, 9 (recommended as a new genus group name for $M$. wollastoni "if it should be deemed necessary to separate this species from the genus Mymar").

Mymar: Dalla Torre 1898: 427 (Mymarilla treated as a synonym).

Mymarilla: Schmiedeknecht 1909: 495 (treated as valid genus with one [incorrectly placed] species but no mention of $M$. wollastoni).

Mymar: Schmiedeknecht 1909: 496 (listed M. Wollastoni [sic] together with three other species [one other of which is also incorrectly placed generically]).

Mymarilla: Ferrière 1952: 43 (treated as valid name for Mymar of authors, not Curtis). Mymarilla: Doutt 1955: 11 (key), 12 (treated as valid genus, but noted that American authors used Mymar as the name for species included under Mymarilla by previous workers).

Mymarilla: Heqvist 1960, 432 (treated as valid genus with one [incorrectly placed] species but no mention of $M$. wollastoni).

Mymarilla: Annecke and Doutt 1961: 31 (discussion of past confusion with Mymar).

Type species. Mymarilla wollastoni Westwood, by monotypy. Transferred (as genotype) to Mymarilla by Heqvist (1960: 432).

The confusion in the use of the name Mymarilla and which species should be placed in the genus continued for over 80 years. Heqvist (1960) was the first to treat M. wollastoni as the genotype of Mymarilla, even as he incorrectly placed Mymar species under it, as did previous authors. As Annecke and Doutt (1961) clarified, wherever previous authors use Mymarilla it was clearly in the sense of Mymar, because the species names mentioned are typical Mymar species.

Diagnosis. The combination of smooth, shiny black body, extremely short mesocutum compared to much longer pronotum, and extraordinary convex and densely setose fore wing distinguish the genus and species from any other Mymaridae.

Mymarilla belongs clearly to the Polynema Haliday group of genera within Mymarini sensu Annecke and Doutt (1961). They suggested that Mymarilla was most similar to Oncomymar Ogloblin from the Juan Fernández Islands. Superficially, the most similar genus is Cremnomymar Ogloblin (including Oncomymar Ogloblin and Scolopsopteron Ogloblin, see below), some of whose species also have a convex fore wing and reduced mesoscutum. The two genera are not closely related; their resemblance is due to adaptations to life on remote, presumably wind-swept, oceanic islands.

I propose instead that Mymarilla is derived from Stephanodes Enock, likely the most closely related genus. Four features, shared with Stephanodes, suggest this: first, the extremely smooth body without trace of microscupture on the mesosoma (Figs 1, $3,4,6,9,10)$; second, the slightly advanced mesothoracic spiracle about midway between the anterior apex of a notaulus and posterolateral angle of the mesoscutum (Figs 3, 4); third, the presence of a metapleural pit (Figs 9, 10); fourth, the fore wings that are held more or less horizontally. In dead specimens of Stephanodes, the fore wings are often horizontal, crossed scissor-like and covering the body, unlike other, related genera in the Polynema-group where the wings (in dead specimens) are almost always 
vertical, directed away from the body. The strong convexity of the fore wings of $M y$ marilla would appear to prevent them from being crossed scissor-like over the body. Yet they are presumably capable of enveloping the metasoma, as pointed out by Westwood who noted "... when shut [the fore wings] form a semiglobular dome over the abdomen" when the wasp is at rest. The densely hairy wing membrane with dark base around each microtrichia would allow for maximum heat absorption and retention.

\section{Mymarilla wollastoni (Westwood)}

http://species-id.net/wiki/Mymarilla_wollastoni

Figs $1-10$

Mymar wollastoni: Westwood 1879: 585 (original desciption).

Mymar wollastonii [sic]: Dalla Torre 1898: 427 (catalogue, unjustified emendation).

Mymarilla wollastoni: Annecke and Doutt 1961: 31 (redescription).

Mymarilla wollastoni: Subba Rao 1976: 90 (diagnosis), 91 (figure).

Remarks. Lectotype female in OUMNH (not examined), designated by Annecke and Doutt (1961), with catalogue number HYME0029 and labeled: "Holotype", "det. D.P. Annecke 25.vii.1960".

Description. Because only one species of Mymarilla is known, the generic and specific features are both described in the species description. Female. Body length $2125(\mathrm{n}=1)$. Body entirely smooth and shiny except for a few small punctures on pronotum. Colour. Head black except mandibles, mesosoma, metasoma medially, and clava; flagellum, and metasoma basally and apically dark brown; scape, pedicel, mandibles, legs, petiole, and ovipositor brownish yellow; all body setae almost white; wings brown behind venation, membrane beyond venation translucent but membrane around each microtrichia back, so wings generally appearing dark. Head. (Figs 3-6) $1.46 \times$ as wide as long, and $1.17 \times$ as wide as high $(406 / 227 / 347)(\mathrm{n}=1)$, in lateral view with anterior surface slightly depressed between toruli then, at level of ventral margin of eye, receding to mouth (Fig. 5). Face measured from eye to eye below toruli about as long as wide, flat above toruli but forming a shallow circular depression medially below toruli; subantennal groove and pits between toruli absent. Torulus about $1.5 \times$ its diameter from thin transverse trabecula and about mid height of eye. Preorbital groove against eye almost to ventral margin of eye (Fig. 5), then extending almost straight to anterolateral angle of mouth margin. Eye (Fig. 5) in lateral view $0.75 \times$ as long as high, not extending to back of head dorsally and separated by more than its own length from back of head ventrally. Malar sulcus absent and malar space almost $0.6 \times$ eye height. Gena narrow dorsally, very wide ventrally. Vertex in lateral view almost flat, sloping anteriorly, forming an obtuse angle to face (separated by transverse trabecula), smoothly merging posteriorly with occiput. Mid ocellus flat in shallow depression, not projecting above surface of vertex and $2 \times$ diameter of small lateral ocellus. Ocelli in high triangle, with POL (168), 


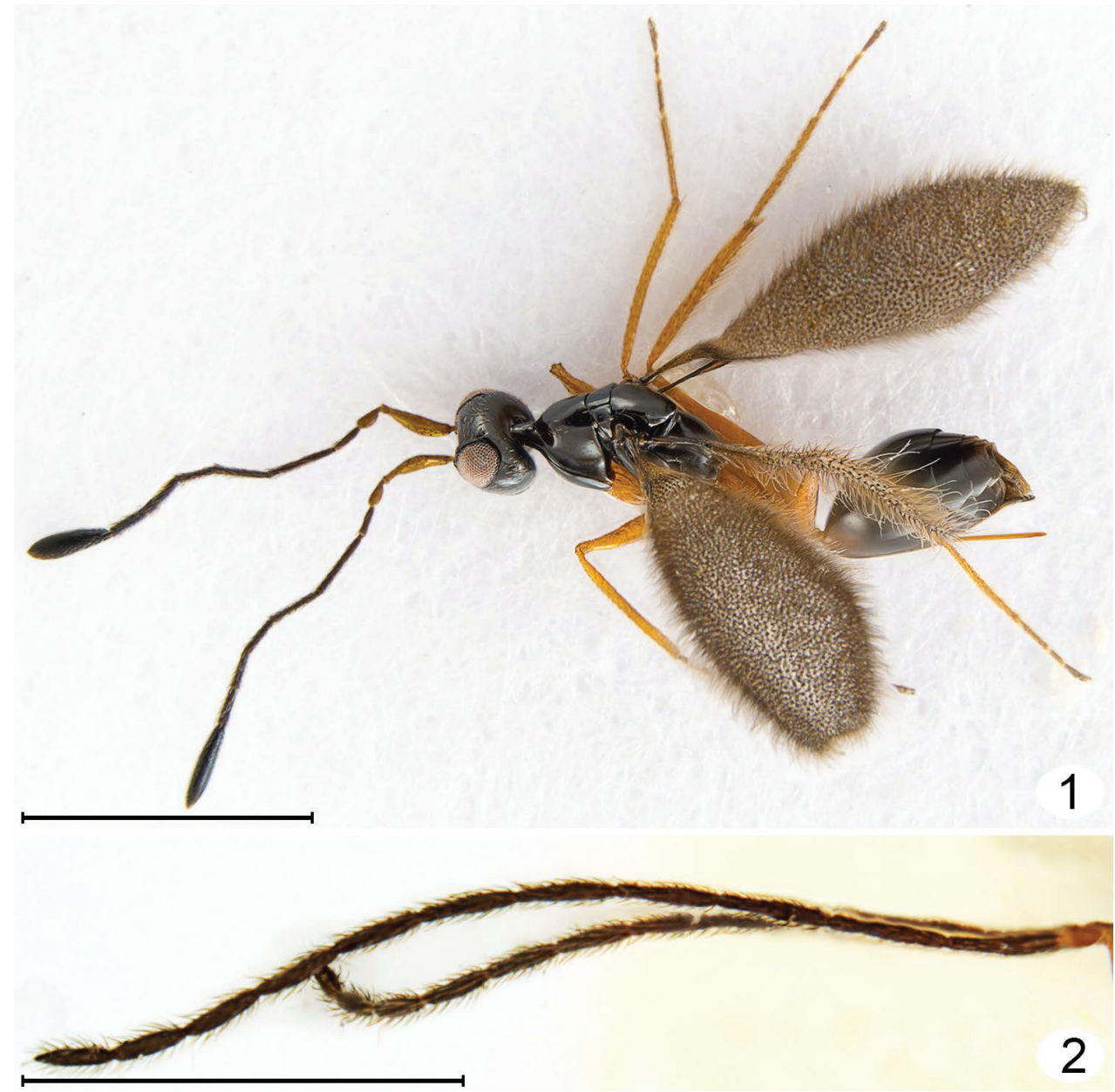

Figures I, 2. Mymarilla wollastoni. I female dorsolateral $\mathbf{2}$ male antennae (pedicel + flagellum). Scale line $=1000 \mu \mathrm{m}$.

1.9× LOL, and LOL (89) 3.0× OOL (30). Mandibles normal, overlapping medially when closed, with 3 teeth. Antenna. Scape about $3.9 \times$ as long as wide, with both inner and outer surfaces apparently smooth, and with radicle short but distinct; pedicel slightly shorter than $\mathrm{fl}_{1}$, about $0.41 \times$ scape length; funicle 6 -segmented; clava unsegmented, slightly longer than scape. Number of mps of funicle segments and clava uncertain (not clearly visible on card mounted specimen). Measurements $(\mathrm{n}=1)$ length/width: scape 267/69, pedicel 109/50, $\mathrm{fl}_{1}$ 129/20, $\mathrm{fl}_{2}$ 267/20, $\mathrm{fl}_{3}$ 198/30, $\mathrm{fl}_{4}$ $149 / 30, f_{5} 149 / 30, f_{6} 149 / 30$, clava 317/80. Mesosoma. About $2.67 \times$ as long as wide, about $1.80 \times$ as long as high, and $1.48 \times$ as wide as high $(\mathrm{n}=1)$. Pronotum (Fig. 3 ) in dorsal view clearly visible, shorter than wide (218: 267), strongly convex, with almost vertical sides flaring outward ventrally and almost horizontal at junction with propleura; pronotum in lateral view strongly triangular. Propleura (Fig. 4) in dorso- 


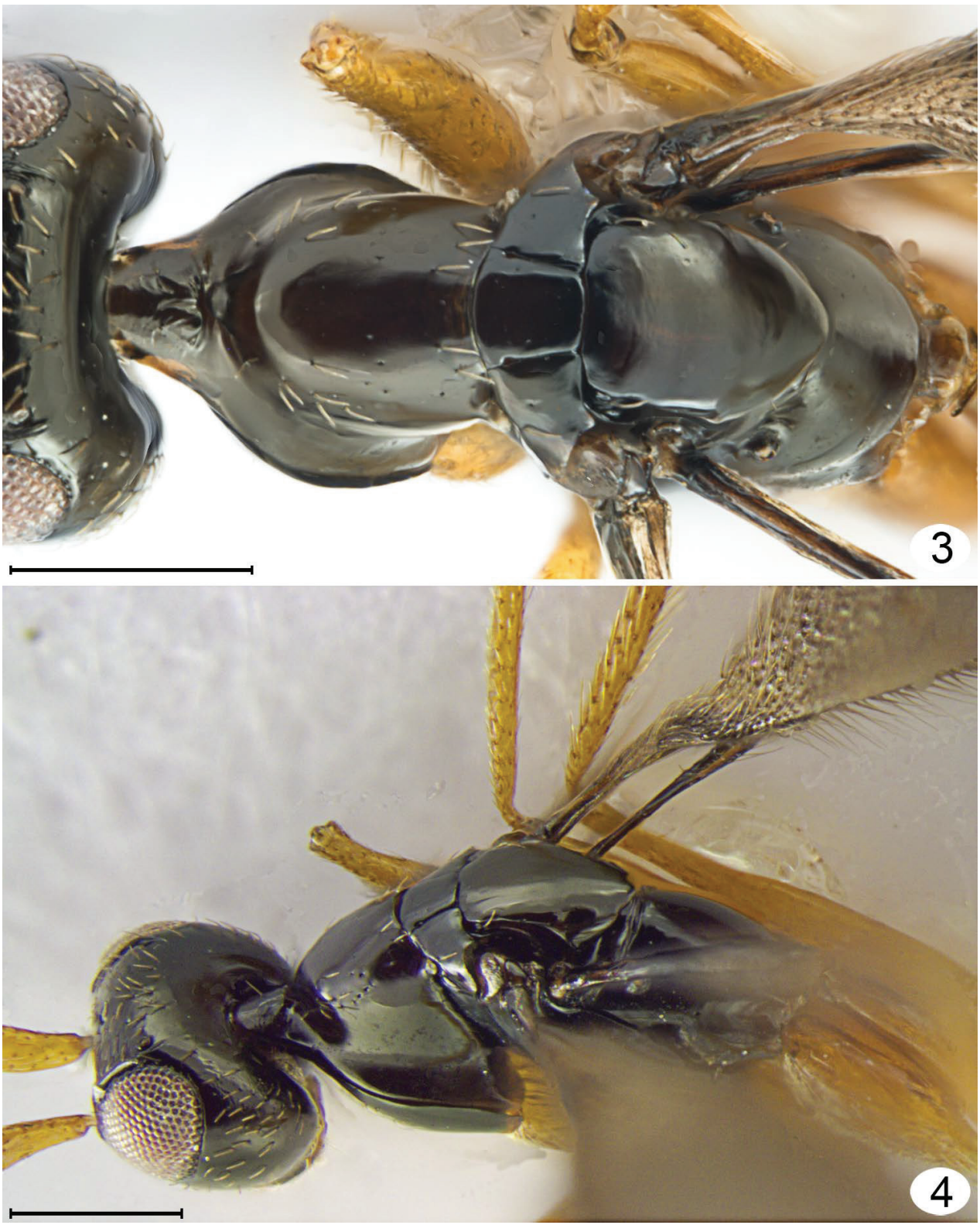

Figures 3, 4. Mymarilla wollastoni. 3 mesosoma, dorsal 4 head and mesosoma, dorsolateral. Scale line $=200 \mu \mathrm{m}$.

lateral view tightly pressed to pronotum laterally and anteriorly, and fused to each other at neck, and, in dorsal view (Fig. 3), slightly extending lateral to pronotum. Neck long (90), clearly separating head from pronotum. Prosternum triangular, strongly appressed laterally to propleura, without median longitudinal line, anterior apex not visible but perhaps closed anteriorly. Mesonotal spiracle (Fig. 6) small, at 

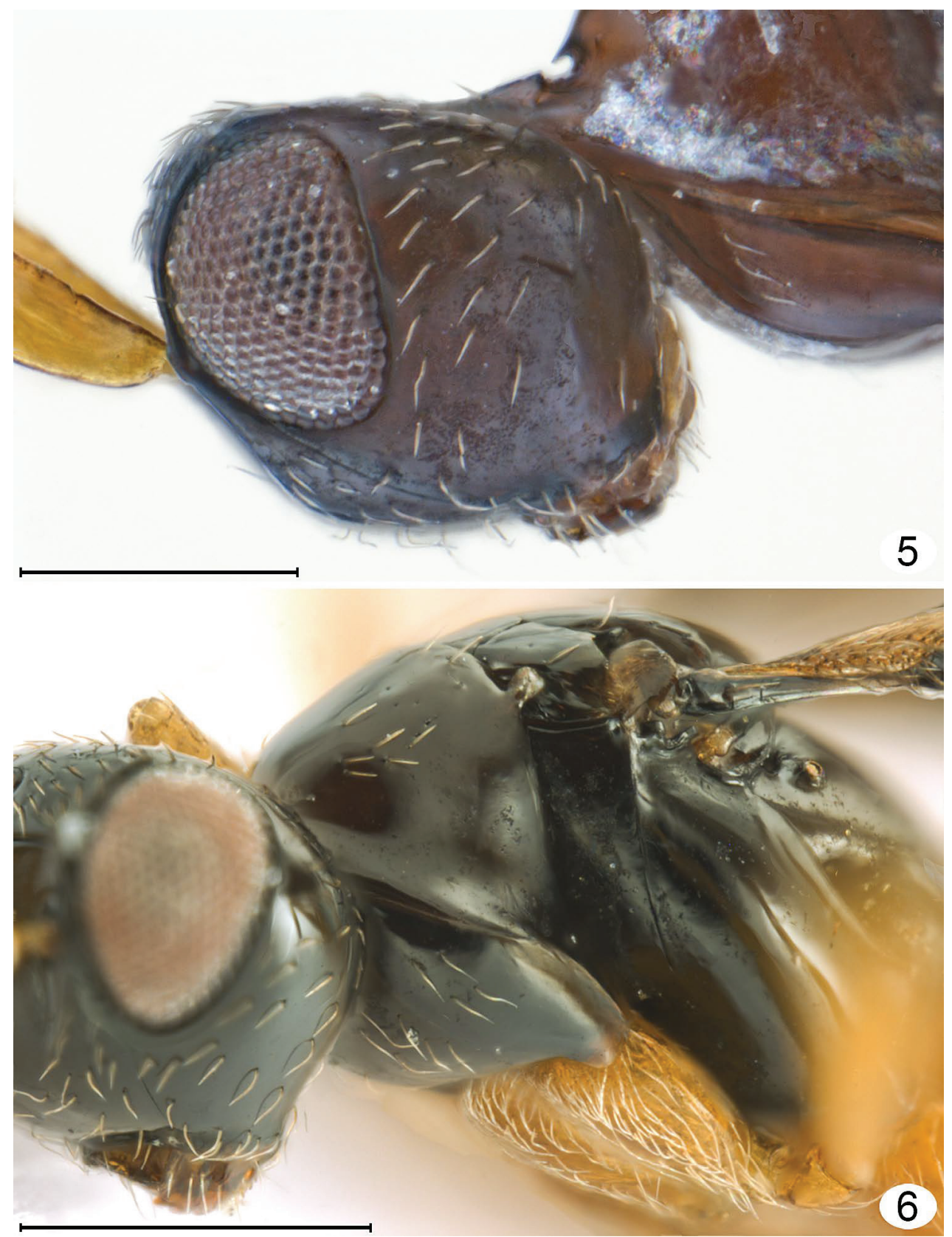

Figures 5, 6. Mymarilla wollastoni. $\mathbf{5}$ head and prothorax, lateral $\mathbf{6}$ head and thorax, anterolateral. Scale line $=200 \mu \mathrm{m}$.

end of short tube, midway between posterolateral angle of mesoscutum and anterior apex of notaulus. Mesoscutum (Fig. 3) smooth and shiny, in lateral view slightly convex, in dorsal view short (99), about $0.4 \times$ as long as pronotum and $0.4 \times$ as long 


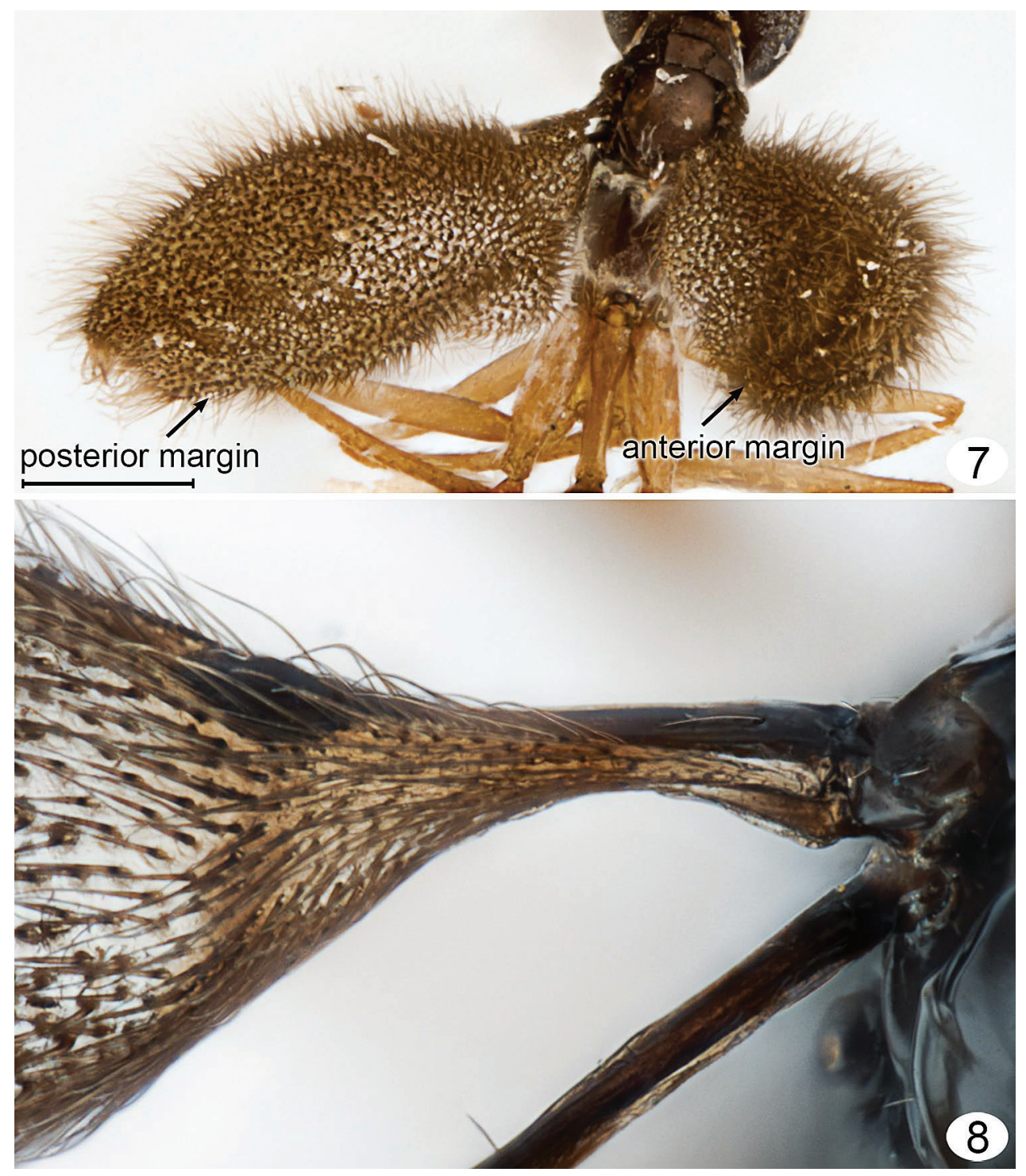

Figures 7, 8. Mymarilla wollastoni. 7 mesosoma, petiole and wings posterodorsal 8 fore and hind wing bases, dorsal. Scale line $=200 \mu \mathrm{m}$.

as wide, with slightly diverging, almost straight notauli, each ending anteriorly in a distinct pit. Axillae not advanced (Figs 3, 4, 9, 10). Mesoscutellum (Fig. 3) almost as long as pronotum (267: 246), slightly overlapping metanotum, without trace of frenal line (frenum therefore not distinguishable). Prepectus (Figs 6, 9, 10) triangular, about $3 \times$ as long as dorsal width. Mesopleuron tightly appressed to prepectus, convex, not divided by suture into mesepisternum and mesipimeron. Metanotum small, triangular, separated from propodeum by wide groove. Metapleuron with a 
large metapleural pit at junction with mesoepisternum. Propodeum (Figs 3, 4, 7, 10) evenly convex, without carinae, with a large pit at anterior margin just anterior to spiracle, with a slightly upturned nucha covering anterior apex of petiole, and with propodeal seta almost at posterior margin. Spiracle small, round, separated by several diameters from anterior margin of propodeum. Wings. Fore wing (Figs $1,7,8)$ deeply convex, with the anterior and posterior margins strongly curving downward, the wing height in lateral view about $0.7 \times$ wing width in dorsal view. Wing behind submarginal vein very narrow, with strongly convex hind margin, abruptly widening beginning at parastigma, generally oval in dorsal view. Entire surface to wing base covered in long microtrichia, those behind venation appressed and those beyond venation semi-erect to erect. Fore wing length $1792(\mathrm{n}=1)$, width 640 , length/width 2.8 , venation length 287 , about $0.18 \times$ forewing length. Submarginal vein black basally, brown apically, and much wider basally than apically; parastigma + stigma black, oval about $1.7 \times$ as wide as base of submarginal vein. Costal cell extremely narrow. Hind wing (Fig. 1) flat to slightly convex, with long marginal setae and erect microtrichia similar to those on forewing, and wing membrane extending almost to base of wing but very narrow behind venation. Hind wing length ca. 1535 , width 77 , venation black, length about $0.3 \times$ wing length. Legs. Long and slender (Figs 1, 7). Metasoma. Petiole length 180, slightly longer than metacoxa, about $6 \times$ as long as wide. Gaster (Fig. 1) smooth and shiny, narrowly oval in cross section (as seen in posterior view), wider dorsally, almost knife-like ventrally at ovipositor. $\mathrm{Gt}_{1}$ about $0.57 \times$ gaster length (870) and almost completely covering gs so petiole apparently attached to tergum, $\mathrm{gt}_{2}-\mathrm{gt}_{5}$ progressively shorter, $\mathrm{gt}_{6}$ and syntergum $\left(\mathrm{gt}_{7}+\mathrm{gt}_{8}\right)$ each about as long as $\mathrm{gt}_{2}$. Spiracle present on $\mathrm{gt}_{6}$, small. Ovipositor length ca. 770, slightly down turned apically, as long as gaster but not exserted beyond gaster, about $1.2 \times$ metatibia length (640).

Male. Colour as in female but body dark brown (possibly due to fading), scape brownish yellow, pedicel light brown, flagellum dark brown. Body length 1843-1894 $(n=2)$. Fore wing length 1664 (hind wing not measurable on pinned specimens), with the edges almost meeting ventrally in one specimen, giving the appearance of a hirsute cigar when seen end on in posterior view (Fig. 7). Antenna. Scape about 3.8x as long as wide, with both inner and outer surfaces apparently smooth. Measurements $(n=1)$ length/width or length for flagellomeres: scape 218/59, pedicel 99/45, $\mathrm{fl}_{1} 277, \mathrm{fl}_{2} 267$, $\mathrm{fl}_{3} 248, \mathrm{fl}_{4} 248, \mathrm{fl}_{5} 223, \mathrm{fl}_{6} 228, \mathrm{fl}_{7} 198, \mathrm{fl}_{8} 198, \mathrm{f}_{9} 178, \mathrm{fl}_{10} 198, \mathrm{fl}_{11}$ 198; total flagellum 2461. $\mathrm{Fl}_{6}$ length/width about 6.0 , with perhaps $8 \mathrm{mps}$ (not clearly visible on card mounted specimen). Metasoma. Gaster length 742-793 $(n=2)$, in lateral view truncate apically.

Material examined. SAINT HELENA. Centre. High Central Ridge, Cabbage Tree Road, 2500', iii.1967, J. Decelle, N. \& J. Leleup (2 males, MRAC); High Peak, $15^{\circ} 58.7^{\prime}$ S, 544.0'W, ca.752m, xii.2005-1.2006, N.P. \& M.J. Ashmole, H. Mendel, E.A. Thorpe, pitfall trap (1 female, BMNH).

Habitat. Westwood (1879) stated that the specimens were swept from low herbage.

Annecke and Doutt (1961) suggested that the wings may be used for floating on air currents. Whether individuals are capable of this, let alone normal flight, is uncertain. 

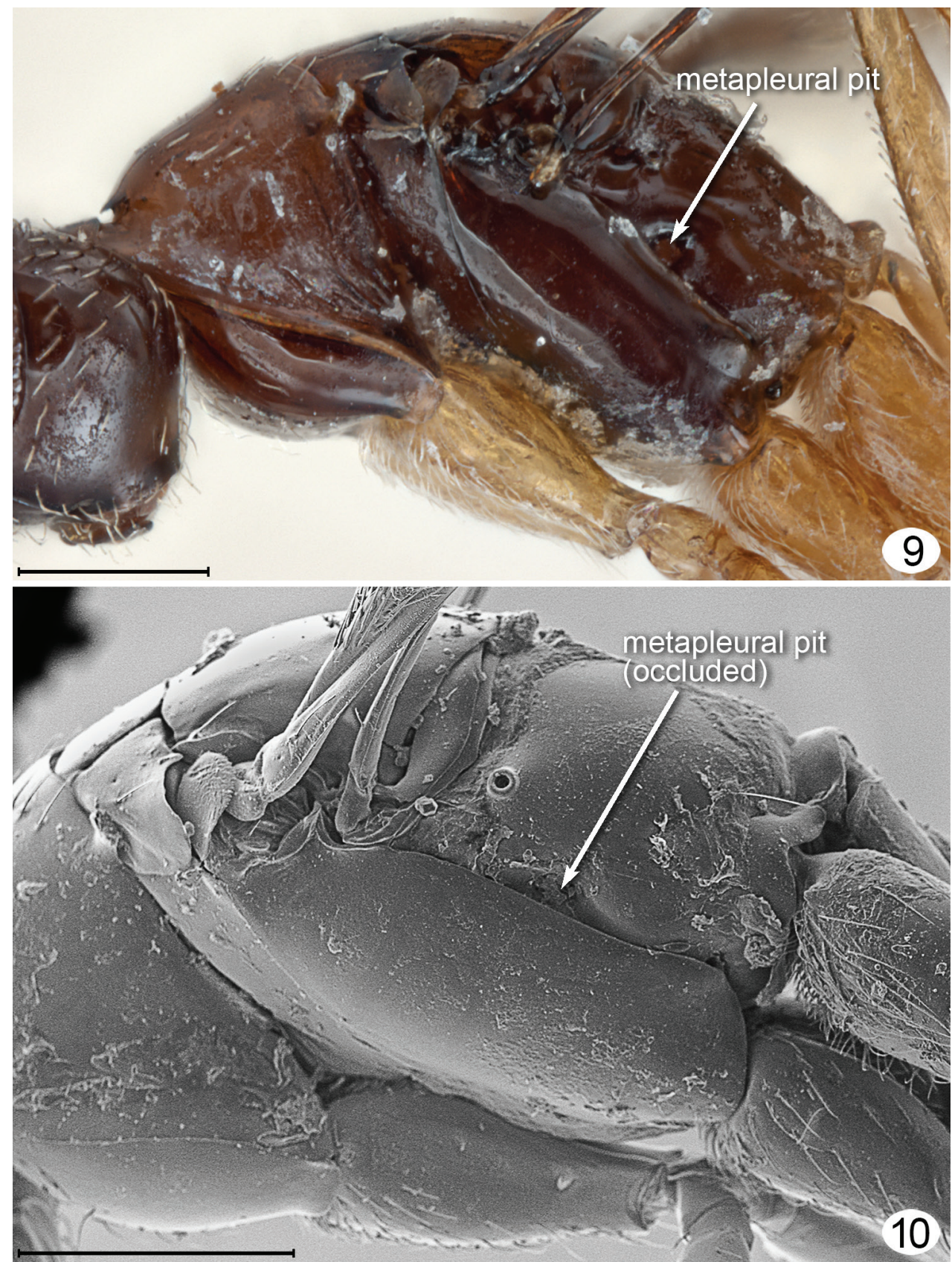

Figures 9, 10. Mymarilla wollastoni. 9 mesosoma lateral 10 mesosoma, lateral, SEM. Scale line $=200 \mu \mathrm{m}$.

The greatly reduced mesoscutum suggests that the flight muscles are so reduced they would be incapable of powered flight. The collection of one female in a pitfall trap suggests that $M$. wollastoni lives near the ground. 


\section{Cremnomymar Ogloblin}

http://species-id.net/wiki/Cremnomymar

Figs 11-14, 20-38

Cremnomymar Ogloblin, 1952: 120 (generic description, two species described, based on males); Ogloblin 1957: 418 (two species described, based on females); Annecke and Doutt 1961: 6 (key), 31 (comments); Fidalgo, 1982: 98 (comparison with Parapolynema);

Scolopsopteron Ogloblin, 1952: 127 (generic description, one species based on two males); Annecke and Doutt, 1961: 6 (key), 30 (comments). syn. n.

Nesopolynema Ogloblin, 1952: 132 (generic description, one species based on a male); Annecke and Doutt 1961: 6 (key), 30 (comments). syn. n.

Oncomymar Ogloblin, 1952: 132 (generic description, one species based on a female); Annecke and Doutt 1961: 6 (key), 30 (comments). syn. n.

Remarks. Ogloblin (1952, 1957) described seven species of Mymaride based on eight specimens from the Juan Fernández Islands, all but one from Masatierra Island (Robinson Crusoe Island). Three were described from females only and four from males only. Scolopsopteron dipteron Ogloblin (Ogloblin 1952) has a fore wing of normal length but unusually narrow and a rudimentary hind wing. Oncomymar kuscheli Ogloblin (Ogloblin 1957) has a fore wing of normal width and length but strongly convex (spoon-shaped) and a rudimentary hind wing. Nesopolynema has a normal fore wing (hind wings missing in Ogloblin's specimen).

It is improbable that the Juan Fernández Islands would have four endemic genera of Mymaridae, as treated by Ogloblin $(1952,1957)$. Above the species category similarities must be used to define collective groups, not differences. If differences are used, then how different must something be to be placed in a different genus? "Different enough" is not an acceptable answer. If it were, the placement of species in genera of finer and finer difference would be the norm, with the result that the genus category would become almost synonymous with the species category, and each genus would contain only one or two species. Unfortunately, Ogloblin sometimes defined genera based on obvious but superficial differences that resulted in oversplitting. I am confident that all seven of Ogloblin's species from the Juan Fernández Islands represent at most different species within a single genus. Indeed some of them have likely been described twice, once from females and once from males.

I examined forty-three specimens (not the types) of Cremnomymar (including the synonyms proposed above), all from Masatierra, the largest of the Juan Fernández Islands. In some of the species the fore wing is fully developed and flat (Fig. 11) but in others it is more or less reduced and convex (Figs 12-14). Depending on the extent of wing reduction the mesothorax is also reduced but the placoid sensilla on the scutellum are always widely separated. The pronotal structure varies from entire, sometimes with indication of a mediolongitutinal line, to being apparently completely divided medially by a complete longitudinal carina. The propodeum in 


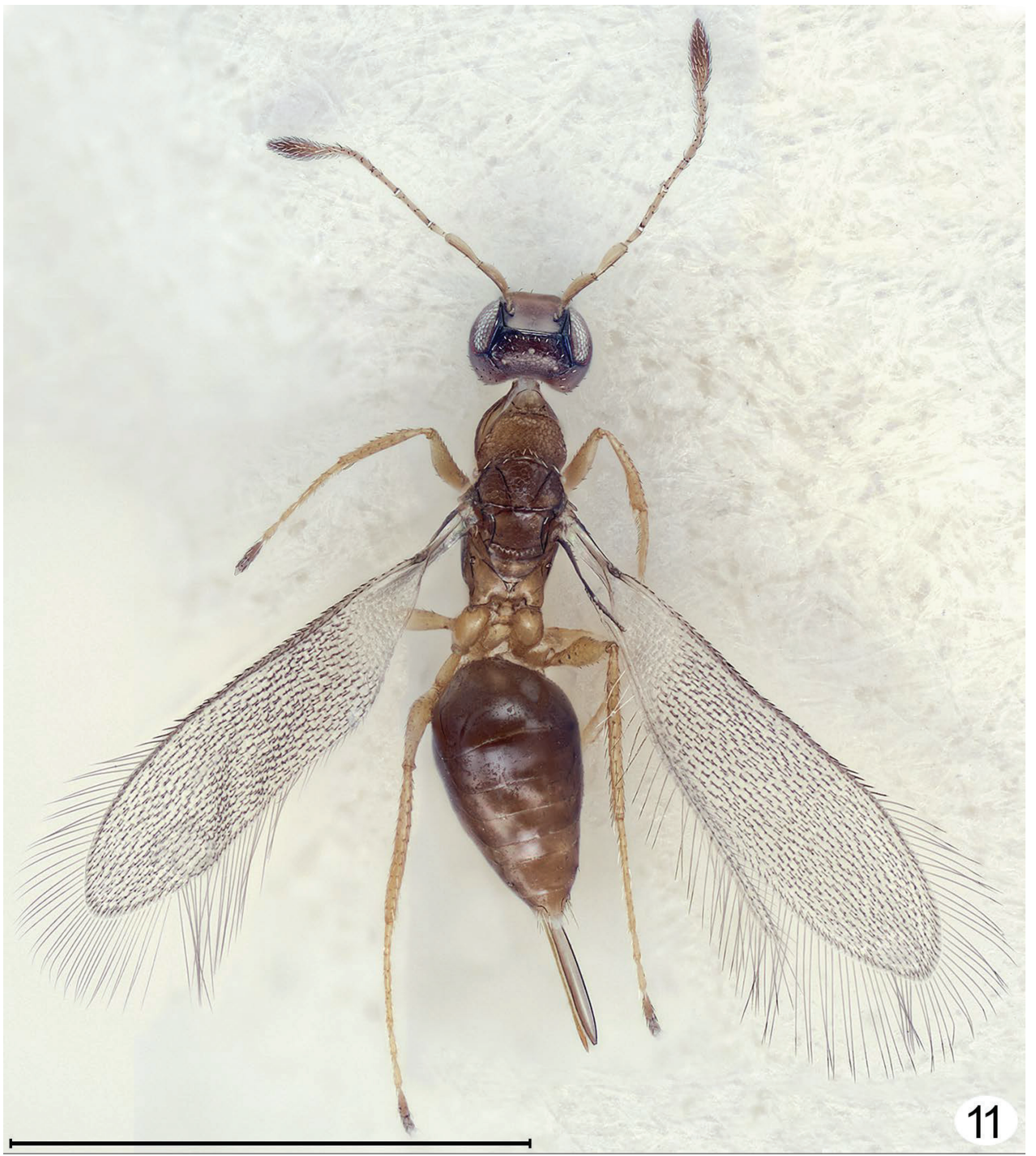

Figure I I. Cremnomymar sp., macropterous female, dorsal (fore wing flat). Scale line $=1000 \mu \mathrm{m}$.

short-winged specimens changes in ways that I consider to be at most of species-level significance, from strongly carinate and with a large, sublateral tooth bearing the propodeal seta, as in fully winged Cremnomymar (Figs 11, 12, 32) to almost smooth (Fig. 14) but still with the propodeal seta on a bump or tooth. Therefore, I propose the above generic synonymies and transfer the included species to Cremnomymar as C. caudatum (Ogloblin 1952), comb. n., C. dipteron (Ogloblin 1957), comb. n., and C. kuscheli (Ogloblin 1952), comb. n. 


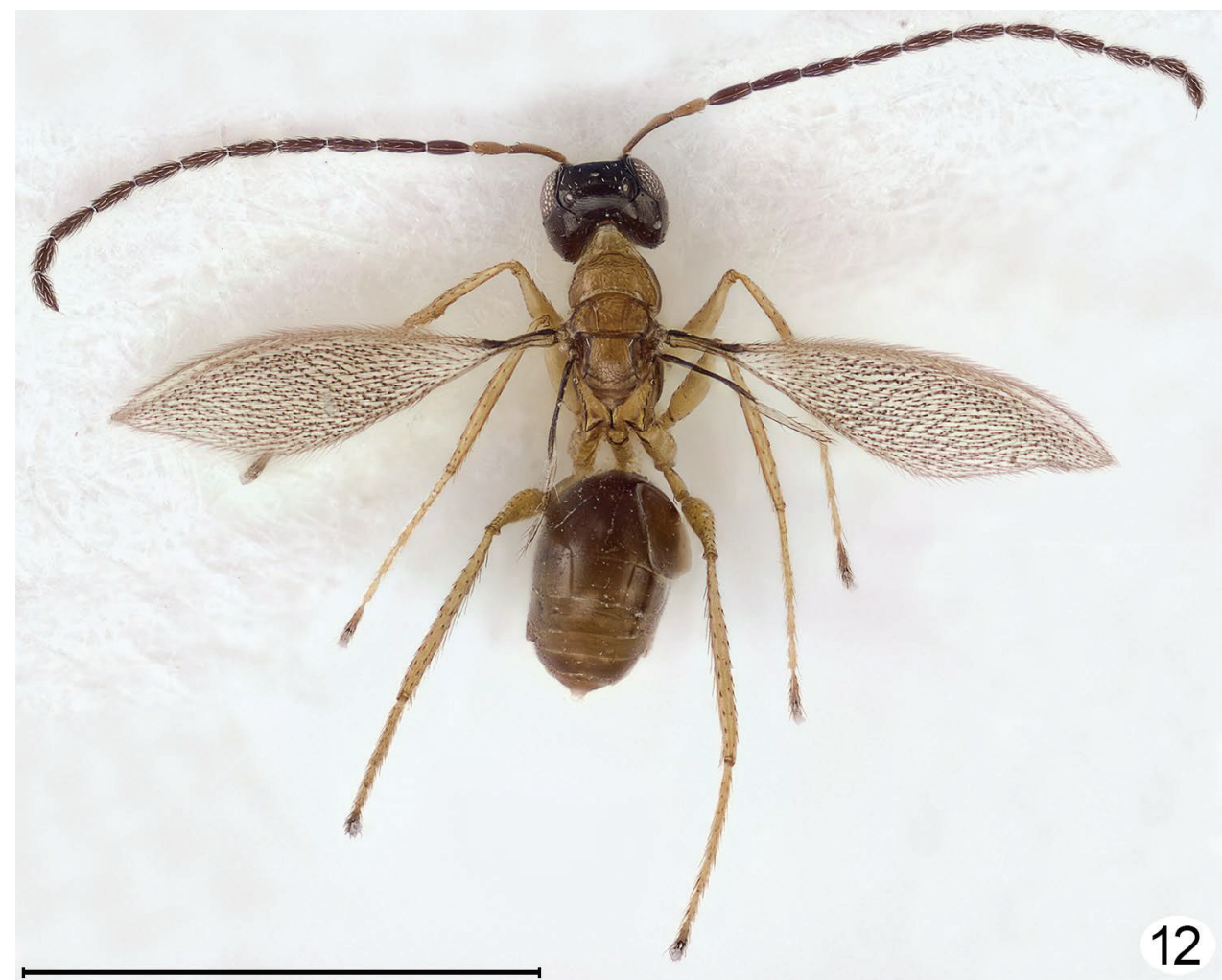

Figure I2. Cremnomymar sp., slightly brachypterous male, dorsal (forewing slightly convex, hind wing brachypterous). Scale line $=1000 \mu \mathrm{m}$.

\section{Biogeography}

St. Helena, with a land area of $122 \mathrm{~km}^{2}$, is a remote island of volcanic origin in the South Atlantic Ocean at $15^{\circ} 54^{\prime}-16^{\circ} 01^{\prime} \mathrm{S}, 5^{\circ} 37^{\prime}-5^{\circ} 47^{\prime} \mathrm{W}$, about $1920 \mathrm{~km} \mathrm{~W}$. of Africa, the nearest continent (Ashmole and Ashmole 2000). The highest elevation is $823 \mathrm{~m}$ and the island's age is estimated to be $14.3 \pm 1.0$ million years. It has a tropical climate moderated by the Benguela Current and southeast trade winds. Two distinct physiographic zones are defined, a wet well-vegetated area above $450 \mathrm{~m}$ and an arid, poorlyvegetated zone below. A considerable proportion of the plant species are endemic.

The Juan Fernández islands with a total land area of $124 \mathrm{~km}^{2}$, almost identical in size to St. Helena, are in the South Pacific Ocean about $600 \mathrm{~km}$ west of Chile. Masatierra Island (Robinson Crusoe Island), at $33^{\circ} 38^{\prime} \mathrm{S}, 78^{\circ} 51^{\prime} \mathrm{W}$ with a land area of about $51 \mathrm{~km}^{2}$ and a $916 \mathrm{~m}$ high point is $3.8-4.2$ million years old. Masafuera Island (Alejandro Selkirk Island) at $33^{\circ} 46^{\prime} \mathrm{S}, 80^{\circ} 47^{\prime} \mathrm{W}$ with a land area of $50 \mathrm{~km}^{2}$ and a 1319 $\mathrm{m}$ high point is $1.0-2.4$ million years old. Santa Clara, the smallest island is $1 \mathrm{~km} \mathrm{SW}$ 


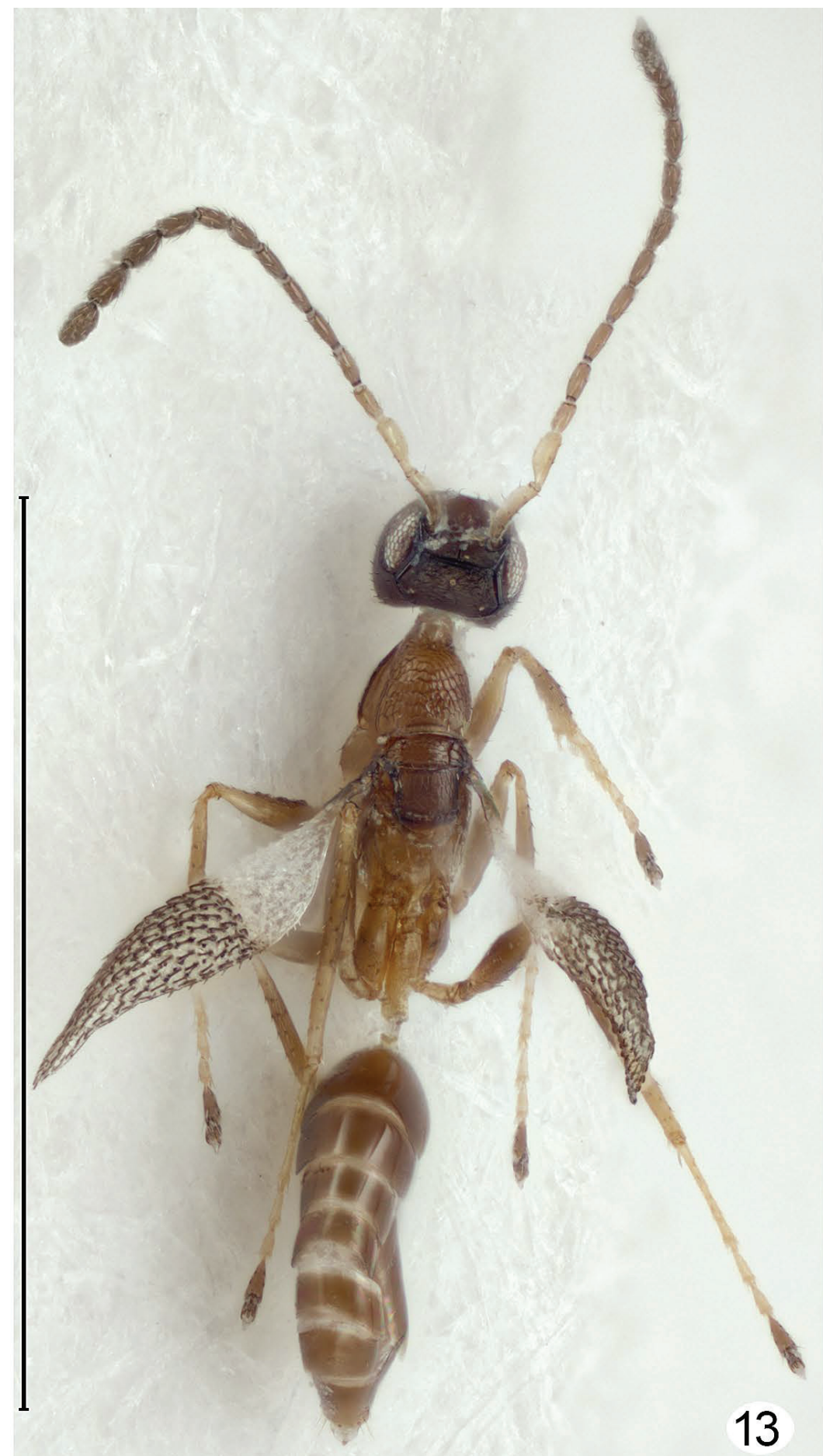

Figure 13. Cremnomymar sp., moderately brachypterous male, dorsal (forewing distinctly convex, hind wing micropterous). Scale line $=1000 \mu \mathrm{m}$. 


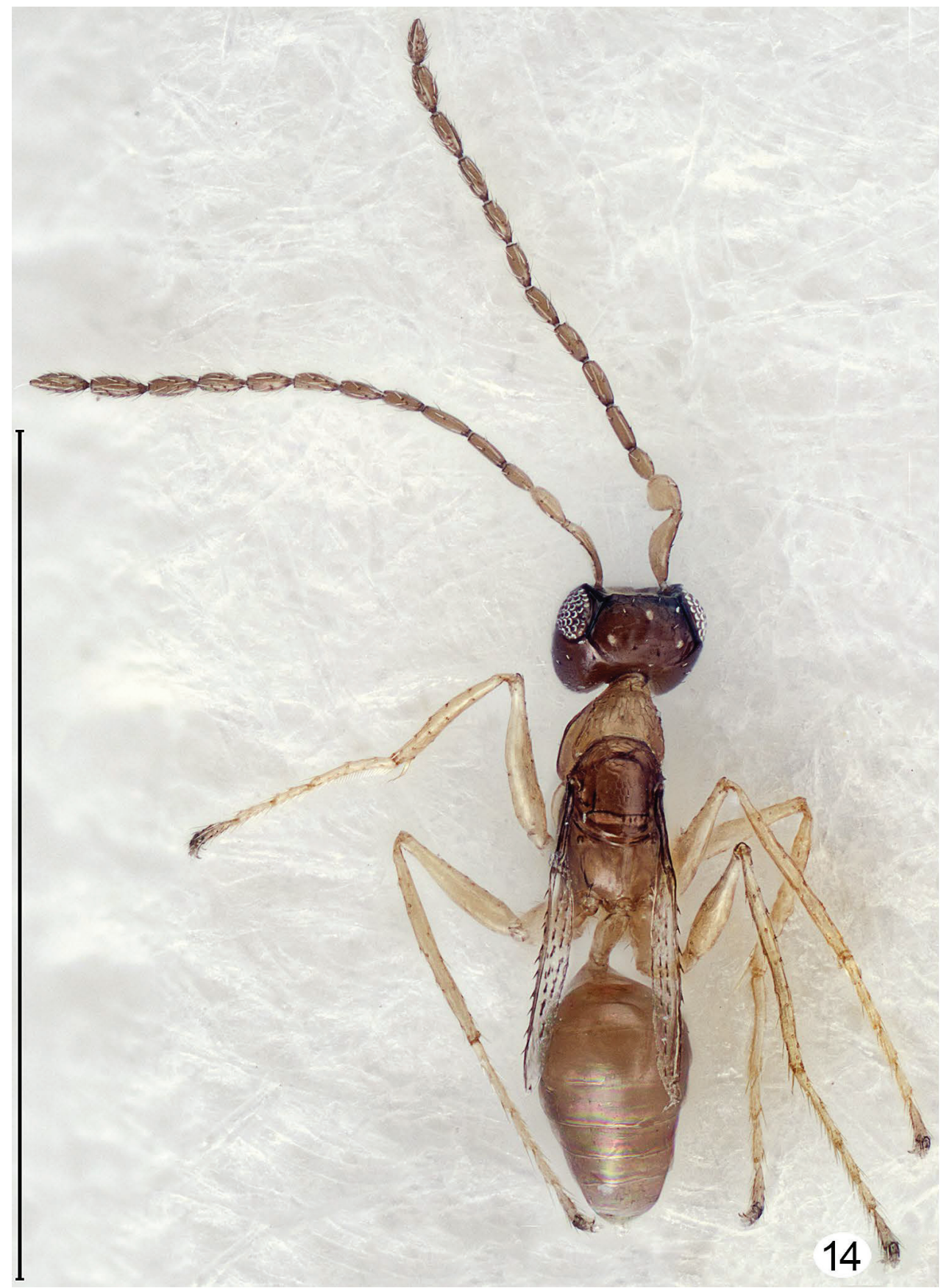

Figure 14. Cremnomymar sp., strongly brachypterous male, dorsal (forewing slightly convex, hind wing absent). Scale line $=1000 \mu \mathrm{m}$. 


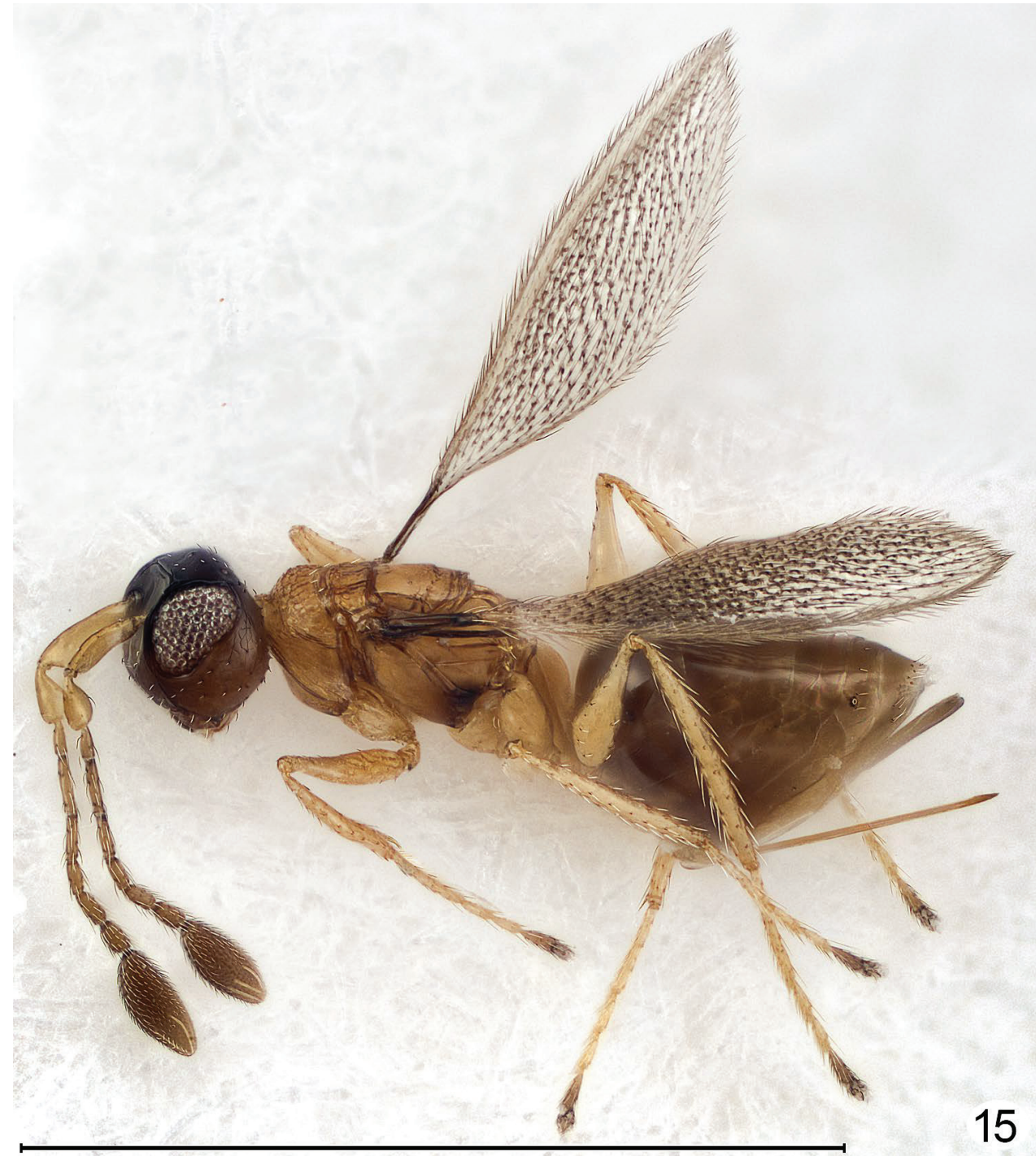

Figure 15. Cremnomymar sp., macropterous female, dorsolateral (fore wing convex, hind wing brachypterous). Scale line $=1000 \mu \mathrm{m}$.

of Robinson Crusoe and 5.8 million years old (Haberle 2009). Over half of the native plants species (126 of 209) are endemic. The climate is subtropical and its climate is affected by the cold Humboldt Current.

Despite being two to three times the age of Santa Clara, the oldest of the Juan Fernández Islands, the remoteness of St. Helena from the nearest continent is likely the main reason why it has only one endemic species of Mymaridae. In contrast, the Juan Fernández Islands have several endemic species, diverse enough to have been placed in separate genera by Ogloblin, who was swayed by the most notable structural differ- 


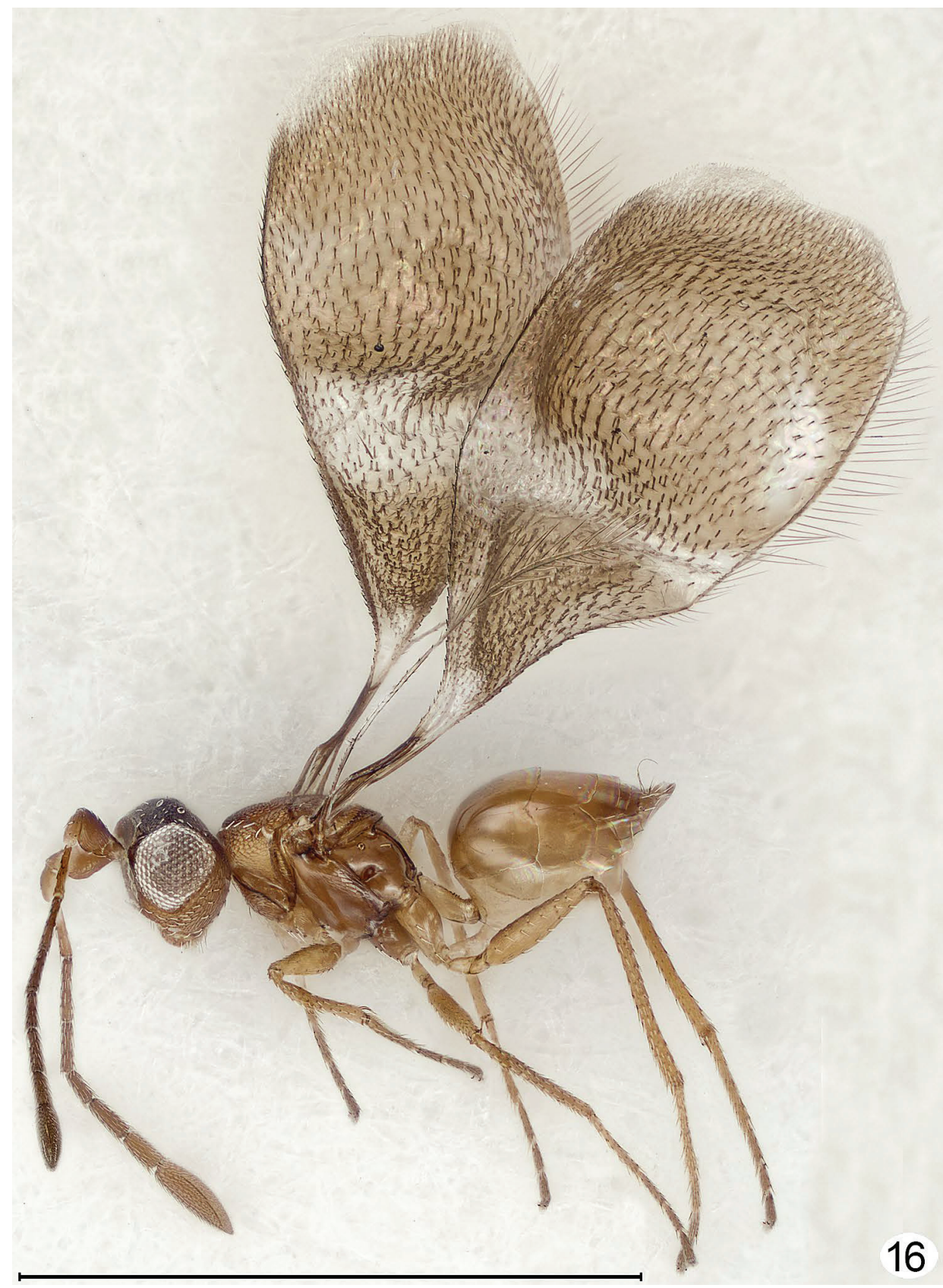

Figure 16. Richteria ara, female, lateral. Scale line $=1000 \mu \mathrm{m}$.

ences among species of three of the four genera, i.e., wing reduction with concomitant modifications of the mesosoma. Another reason for the difference in faunas of the two groups of islands is the harsher climate on the Juan Fernández Islands (subtropical) 


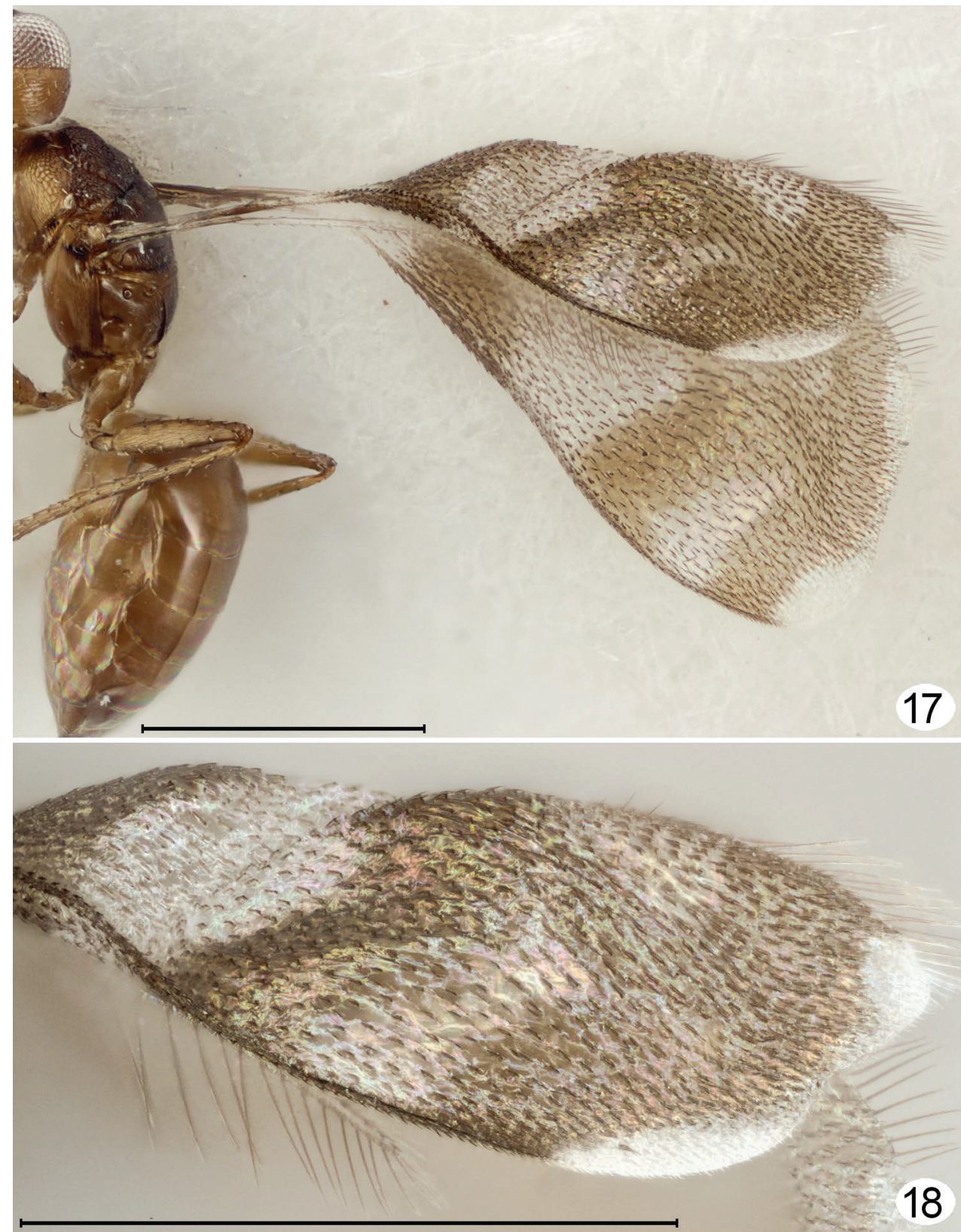

Figures 17, 18. Richteria ara, male. $\mathbf{7}$ lateral, wings dorsoposterior $\mathbf{1 8}$ fore wing detail. Scale line $=500 \mu \mathrm{m}$.

compared to St. Helena (tropical), causing a greater selection pressure on any terrestrial organism established there and therefore a greater likelihood of diversification into several species. Two other reasons are: 1 ) there is greater chance of continental species reaching the Juan Fernández Island than St. Helena, so multiple introductions could 


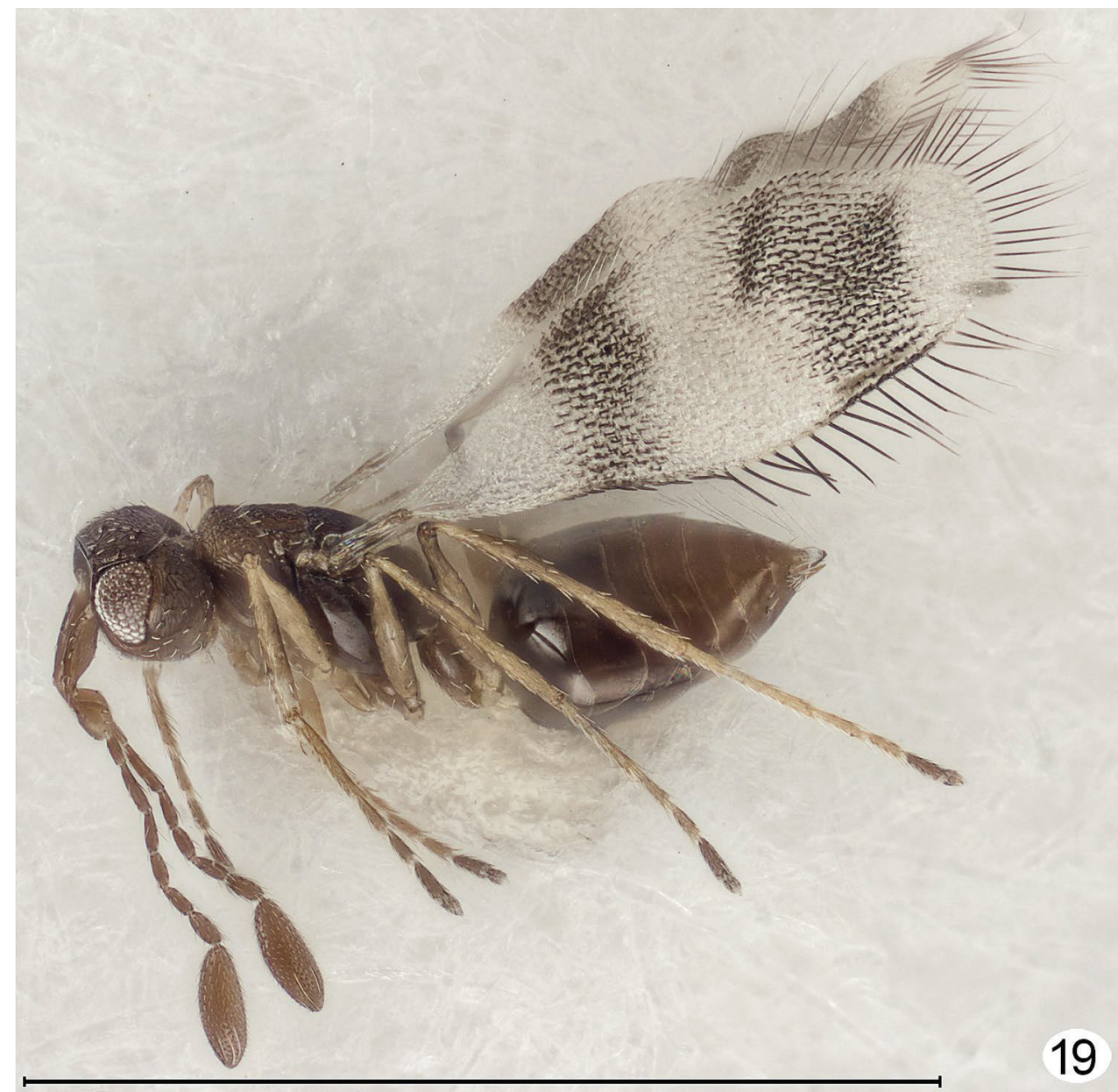

Figure 19. Parapolynema sp., female, dorsolateral. Scale line $=1000 \mu \mathrm{m}$.

account for the diversity of Cremnomymar species on Masatierra; and 2) the fauna (and flora) of St. Helena has been much more affected by human activity, possibly resulting in the disappearance of other species of Mymaridae that may have existed there, leaving only M. wollastoni among the endemic Mymaridae.

One specimen of Parapolynema Fidalgo was seen, collected in Bolivia, La Paz, Sorata environs, 3200m, 20.iv.1997, L. Masner, sweeping open scrub (1 female, CNC). Fidalgo $(1982,1991)$ stated that Parapolymema is most similar to Cremnomymar, based on fore wing structure (Fig. 15) and propodeal seta set on a similar (as in some Cremnomymar), distinct protuberance. But the fore wing also is remarkably similar to that of Richteria Girault (Figs 16-18). The endemic Mymaridae on the Juan Fernández Islands are probably derived from specimens of Parapolynema that arrived there from southern South America but there seems to be a link to the New Zealand/Australian fauna and all three genera may be Gondwanan remnants. 

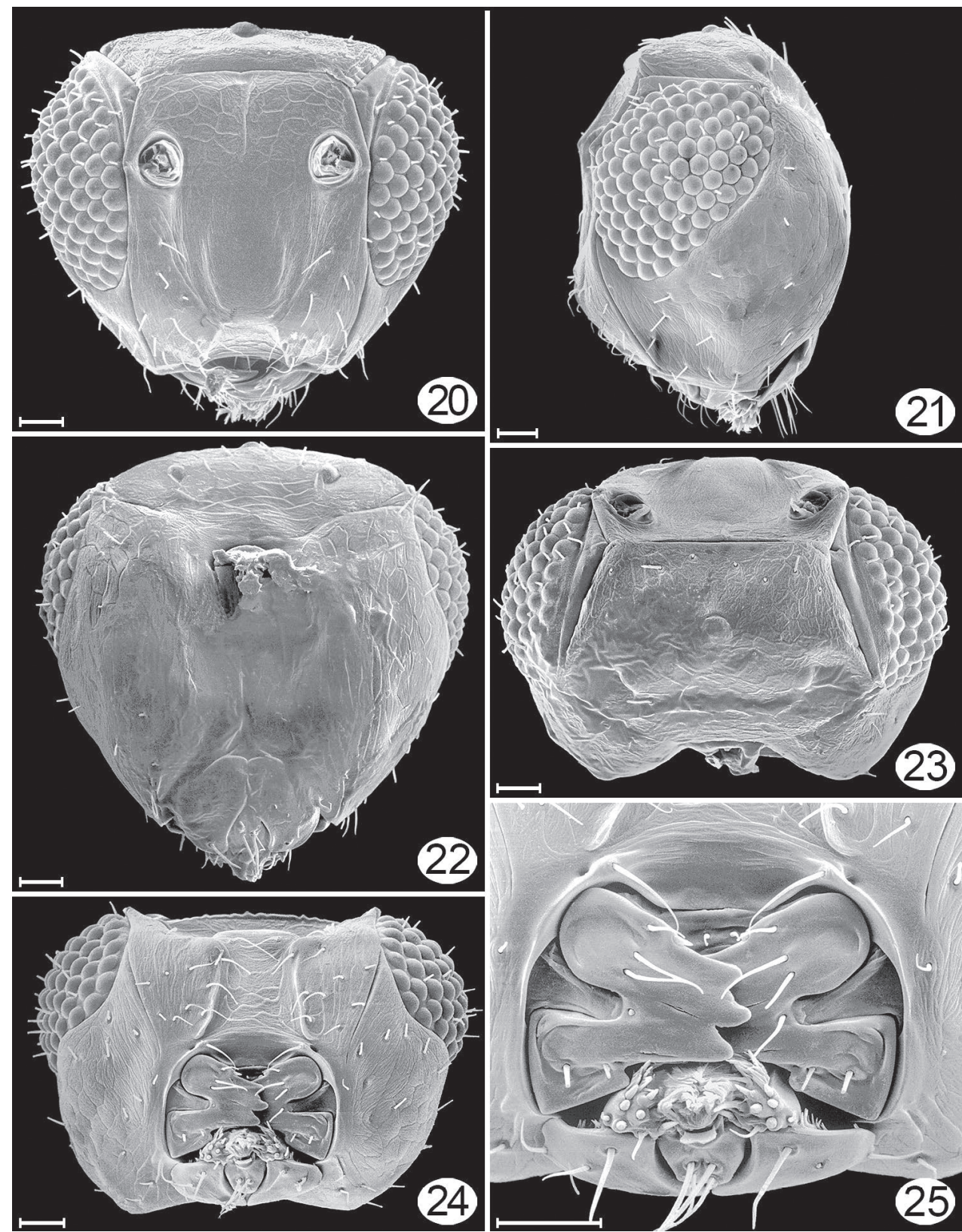

Figures 20-25. Cremnomymar sp. (macropterous), micrographs. 20 head, anterior $\mathbf{2} \mathbf{I}$ head, lateral $\mathbf{2 2}$ head, posterior (sculpture hidden by glue except laterally and dorsally) $\mathbf{2 3}$ head, dorsal $\mathbf{2 4}$ head, ventral 25 mouthparts. Scale lines $=20 \mu \mathrm{m}$. 

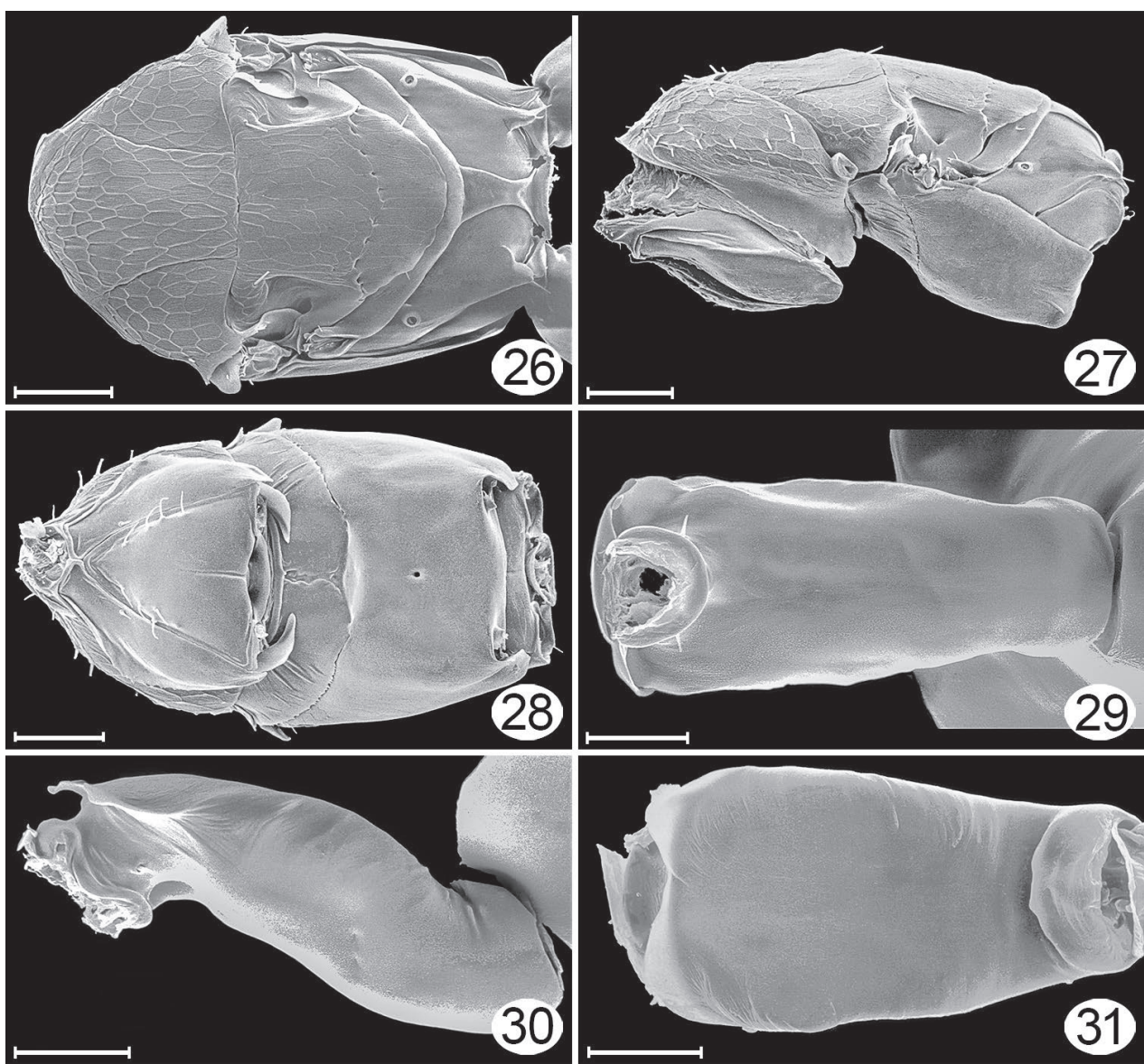

Figures 26-3 I. Cremnomymar sp. (macropterous), micrographs. 26 mesosoma (pronotum missing), dorsal 27 mesosoma, lateral $\mathbf{2 8}$ mesosoma, ventral 29 petiole, dorsal $\mathbf{3 0}$ petiole, lateral $\mathbf{3 I}$ petiole, ventral. Scale lines for $\mathbf{2 6 - 2 8}=50 \mu \mathrm{m}$; for $\mathbf{2 9}-\mathbf{3 1}=20 \mu \mathrm{m}$.

\section{Wing modification in Mymaridae}

The wings of Mymaridae vary considerably in shape, perhaps more than in most other families of Chalcidoidea. In a normal, fully developed (macropterous) wing the surface is flat, with the length several times greater than width and with a more or less rounded apex. Variations in shape are due partly to changes in length and width and partly to changes in outline, particularly of the posterior margin and wing apex. Depending on the genus and species a full length fore wing may become narrower so that length becomes even greater relative to width. The extremes are $2.5 \times$ as long as wide in Paranaphoidea Girault (Lin et al. 2007, fig. 206) and 30x as long as wide in Cleruchus biciliatus (Ferrière) (Ferrière 1952). Hind wing shape varies only slightly because it is generally linear to begin with. Variation in a full length hind wing is therefore mainly in width, from extremely narrow, thread-like, e.g., Mymar (Huber et al. 2009, fig. 55) to wide, e.g., Par- 


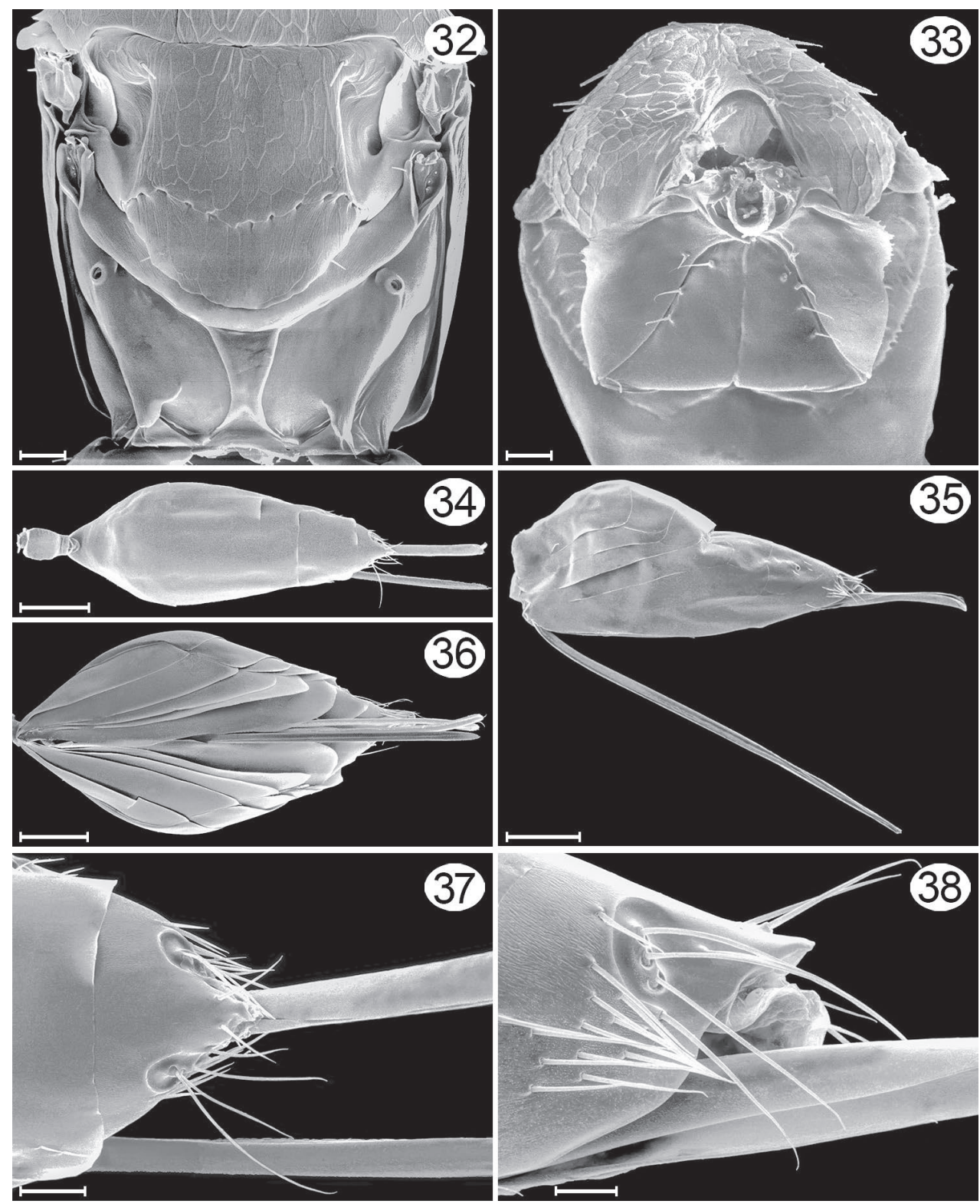

Figures 32-38. Cremnomymar sp. (macropterous), micrographs. 32 frenum + propodeum, dorsal $\mathbf{3 3}$ mesosoma, ventroanterior $\mathbf{3 4}$ metasoma, dorsal $\mathbf{3 5}$ metasoma, lateral $\mathbf{3 6}$ metasoma, ventral $\mathbf{3 7}$ apex

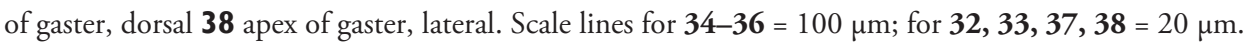

anaphoidea (Lin et al. 2007, fig. 206); rarely the hind wing may be curved, with the anterior and posterior margins distinctly convex and concave, respectively. Despite all this variation the wings remain two dimensional. Most of the range of wing shapes and sizes is illustrated in generic treatments of Mymaridae by Subba Rao (1983) for the Oriental 
region, Noyes and Valentine (1989) for New Zealand, Yoshimoto (1990) for the Western Hemisphere, Huber (1997) for North America, Lin et al. (2007) for Australia, Huber et al. (2009) for the Arabian Peninsula, and Luft Albarracin et al. (2009) for Argentina.

Wing reduction (brachyptery, microptery) or complete loss (aptery) usually occurs where there a strong selection pressure against having fully developed wings. Reduction in length may be slight shorter than normal, to extremely short, at least in one sex (usually the female) of at least one species of a genus. Species with wings reduced or absent occur on all continents, mostly in species that search for host eggs in confining places where wings would be a hindrance, e.g., in soil, leaf litter, or in tubules of bracket fungi (some Cleruchus spp.) or in windy places, e.g., small, remote oceanic islands and high elevations on mountains. All three species (100\%) of Mymaridae found on small islands (Campbell I., Auckland I., South Georgia) at more than $45^{\circ}$ south are wingless or micropterous. Each species is placed in its own genus and each genus is evidently related to a genus on the nearest mainland or is a wingless species with winged congeners in New Zealand, and South America, respectively. For example, on South Georgia (at or near sea level) Notomymar is completely wingless, whereas at $4100 \mathrm{~m}$ in Ecuador (Yoshimoto 1990) the species there is micropterous, and at low altitude in Chile, the species (undescribed?) is/are fully winged.

On remote oceanic islands between $30^{\circ}-45^{\circ} \mathrm{S}$ Mymaridae are reported so far only from the Juan Fernández Islands (Cremnomymar, 7 described spp., but some probably synonyms), Norfolk Island (Cybomymar Noyes \& Valentine [Lin et al. 1997], 1 sp.), and Lord Howe Island (Anagroidea sp., new record). Wingless or short-winged species represent at least $20 \%$ of the fauna, excluding genera/species likely introduced over the past few hundred years by humans. In contrast, Mymaridae from continents south of $30^{\circ} \mathrm{S}$ contain a low percentage of short winged or wingless species. The exception is New Zealand (a large continental island) with 17 of 42 genera that contain at least one flightless species (Noyes and Valentine 1989: 8).

Between the tropics of Cancer and Capricorn no wingless or short winged species have yet been recorded on the relatively well studied but still poorly known (for Mymaridae) Pacific oceanic islands: Micronesia (Doutt 1955), Fiji (Huber 2009), Galapagos Islands (Huber, unpublished), Hawaiian Islands (Beardsley and Huber 2000) and, in the Atlantic Ocean, the Cape Verde Islands (Viggiani and Jesu 1995). Northern Hemisphere islands north of the tropic of Cancer are almost all in the North Atlantic Ocean. They are either too close to continents to develop endemic faunas that include short-winged or wingless species or they are too far north and therefore too cold for most insects to survive. They have generally been poorly explored, except Madeira (Graham 1979, 1983, 1988).

Curvature of the fore wing so it becomes convex or dome-shaped, i.e., it is no longer flat but clearly three-dimensional, occurs in at least one species of four genera: Cremnomymar Ogloblin (Figs 12, 13), Mymarilla (Figs 1, 7), Parapolynema Fidalgo (Fig. 15), so far known from Argentina and Bolivia, and Richteria (Figs 16-18), so far known from Australia and New Zealand. On wind-swept islands convex wings may perhaps have survival value by enveloping the posterior part of the mesosoma and the metasoma, either for greater heat absorption and retention or to reduce the chance of 
being blown away. But species of Parapolynema and Richteria do not necessarily occur in harsh environments so there evidently are other reasons for having a more or less convex fore wing. Interestingly, the fore wings of both genera have a double dome, in contrast to the single dome of Mymarilla and some Cremnomymar.

It would be interesting to find out if Mymaridae occur on other remote Southern Hemisphere islands, particularly those south of $30^{\circ}$. Collecting in a diversity of microhabitats using yellow pan traps or sifting of soil and whatever vegetation is present is required because any Mymaridae present are almost certain to be wingless or short winged.

\section{Acknowledgements}

I thank E. S. Ryder (BMNH) and E. De Coninck (MRAC) for the loan of specimens and, particularly, N. Dale-Skey Papilloud (BMNH) for sending me images of the labels on Wollaston's Mymarilla specimens in Oxford and helping out in other ways. My technician, J. Read, is gratefully acknowledged for taking the photographs and compiling the figures and my previous technician, K. Bolte, is thanked for the scanning electron micrographs.

\section{References}

Annecke DP, Doutt RL (1961) The genera of the Mymaridae. Hymenoptera: Chalcidoidea. Entomology Memoirs. Department of Agricultural Technical Services, Republic of South Africa 5: 1-71.

Ashmole P, Ashmole MJ (2000) St Helena and Ascension Island: a natural history. Anthony Nelson, Oswestry, UK. Current distributor: http://www.kidstonmill.org.uk

Beardsley JW, Huber JT (2000) Key to genera of Mymaridae from the Hawaiian Islands, with notes on some of the species (Hymenoptera: Mymaridae). Proceedings of the Hawaiian Entomological Society 34: 1-22.

Bolte KB (1996) Techniques for obtaining scanning electron micrographs of minute arthropods. Proceedings of the Entomological Society of Ontario 127: 67-87.

Dalla Torre CG de (1898) Subfam. Mymarinae. Catalogus hymenopterorum hucusque descriptorum systematicus et synonymicus. Vol. 5: Chalcididae et Proctotrupidae. Guilelmi Engelmann, Lipsiae [Leipzig], 422-431.

Doutt RL (1955) Insects of Micronesia. Hymenoptera: Trichogrammatidae and Mymaridae. Insects of Micronesia 19(1): $1 \mathrm{~B} 17$.

Ferrière Ch (1952) Un nouveau genre de Mymaride (Hym.). Mitteilungen der Schweizerischen Entomologischen Gesellschaft 25: 41-43.

Fidalgo AP (1982) Sobre un nuevo genero y especie de mimarido de Argentina (Hymenoptera: Chalcidoidea). Revista de la Sociedad Entomologica Argentina 41: 97-102.

Fidalgo P (1991) Sobre Parapolynema Fidalgo, 1991, con descripcion de una neva especie (Hymenoptera; Mymaridae). Revista de la Sociedad Entomologica Argentina 49: 152-155. 
Gibson GAP (1997) Chapter 2. Morphology and terminology. In: Gibson GAP, Huber JT, Woolley JB (Eds) Annotated keys to the genera of Nearctic Chalcidoidea (Hymenoptera). NRC Research Press, Ottawa, 16-44.

Graham MWR de V (1979) The Chalcidoidea (Hymenoptera) of Madeira : a preliminary list. Entomologist's Gazette 30: 271-287.

Graham MWR de V (1983) Madeira insects: faunal notes, additions and descriptions of new species of Chalcidoidea (Hymenoptera). Boletim do Museu Municipal do Funchal 35(151): 5-40.

Graham MWR de V (1988) Madeira insects: additions to the list of parasitic Hymenoptera, with some comments on problems of conservation. Boletim do Museu Municipal do Funchal 40(198): 75-92.

Haberle S (2009) Juan Fernandez Islands. In: Gillespie RG, Clague DA (Eds) Encyclopedia of Islands. University of California Press, Berkeley, CA, 507-509.

Heqvist KJ (1960) Hymenoptera (Chalcidoidea) Mymaridae. South African Animal Life Results of the Lund University expedition in 1950-1951, 7: 423-432.

Huber JT (1997) Chapter 14. Mymaridae. In: Gibson GAP, Huber JT and Woolley JB (Eds) Annotated keys to the genera of Nearctic Chalcidoidea (Hymenoptera). NRC Research Press, Ottawa, 499-530.

Huber JT (2009) Introduction to the Mymaridae (Hymenoptera) of Fiji, with description of two new species and comparison with the fairyflies of other Pacific Islands. Bishop Museum Occasional Papers 106: 17-34.

Huber JT (2012) Revision of Ooctonus (Hymenoptera: Mymaridae) in the Nearctic region. Journal of the Entomological Society of Ontario 143: 15-105

Huber JT, Viggiani G, Jesu R (2009) Order Hymenoptera, family Mymaridae. In: van Harten A (Ed) Arthropod Fauna of the UAE. Volume 2, 270-29.

Lin N-Q, Huber JT, La Salle J (2007) The Australian genera of Mymaridae (Hymenoptera: Chalcidoidea). Zootaxa 1596: 1-111.

Luft Albarracin E, Triapitsyn SV, Virla EG (2009) Annotated key to the genera of Mymaridae (Hymenoptera: Chalcidoidea) in Argentina. Zootaxa 2129: 1-28.

Noyes JS, Valentine EW (1989) Mymaridae (Insecta: Hymenoptera) - introduction, and review of genera. Fauna of New Zealand, 17. 95 pp.

Ogloblin AA (1952) Los insectos de las islas Juan Fernandez 12. Mymaridae (Hymenoptera). Revista Chilena de Entomología 2: 119-138.

Ogloblin AA (1957) Los insectos de las islas Juan Fernandez 35. Mymaridae, Ceraphronidae, Diapriidae y Scelionidae (Hymenoptera). Revista Chilena de Entomología 5: 413-444.

Schmiedeknecht O (1909) Hymenoptera Fam. Chalcididae. Genera Insectorum 97: 1-550.

Subba Rao BR (1976) Narayana, gen. nov. from Burma and some synonyms (Hymenoptera : Mymaridae). Oriental Insects 10: 87-91.

Subba Rao BR, Hayat M (1983) Key to the genera of Oriental Mymaridae, with a preliminary catalog (Hymenoptera: Chalcidoidea). Contributions to the American Entomological Institute 20: $125-150$.

Viggiani G, Jesu R (1995) [1993] New species of Mymaridae from Cape Verde Islands (Hymenoptera: Chalcidoidea). Bollettino del Laboratorio di Entomologia Agraria "Filippo Silvestri" 50: $93-107$. 
Westwood JO (1879) Descriptions of some minute hymenopterous insects. Transactions of the Linnean Society of London (Zoology) 1(8): 583-593. doi: 10.1111/j.1096-3642.1879. tb00496.x

Wetterer JK, Espadaler X, Ashmole NP, Mendel H, Cutler C, Endeman J (2007) Ants (Hymenoptera: Formicidae) of the South Atlantic islands of Ascension Island, St Helena, and Tristan da Cunha. Myrmecological News 10: 29-37.

Yoshimoto CM (1990) A review of the genera of New World Mymaridae (Hymenoptera: Chalcidoidea). Flora \& Fauna Handbook no. 7. Sandhill Crane Press, Gainesville, 166 pp. 